\title{
ADEQUAÇÃO DE ESTRUTURA FÍSICA DE UNIDADES DE ALIMENTAÇÃO E NUTRIÇÃO NA CIDADE DE SÃO PAULO - SP
}

\section{APPROPRIATENESS OF PHYSICAL STRUCTURE OF FOOD AND NUTRITION UNITS IN THE CITY OF SAO PAULO - SP}

\author{
Ana Paula Costa dos Santos ${ }^{1}$, Valdirene F. Neves do Santos ${ }^{1 *}$ \\ ${ }^{1}$ Universidade Paulista, São Paulo, São Paulo, Brasil \\ *Autor correspondente: Universidade Paulista ( UNIP). Rua Antônio de Macedo, 505, Pq \\ São Jorge. São Paulo. CEP 03087-040. Correio eletrônico - val_usp@hotmail.com

\section{RESUMO}

Ao longo das décadas as Unidades de Alimentação e Nutrição (UANs) têm crescido de maneira significativa, porém muitas vezes com padrões de estruturas físicas inadequadas, onde o grande desafio é rever os conceitos e sua adequação. São considerados padrões de estruturas físicas adequadas à forma retangular de layout, aspectos como iluminação, ventilação, pisos e paredes, portas e janelas. O presente projeto tem como objetivo avaliar a adequação de estrutura física das Unidades de Alimentação e Nutrição, na cidade de São Paulo. Trata-se de um estudo descritivo, de natureza transversal, numa perspectiva comparativa com as legislações vigentes: RDC no 275 de 2002, RDC n ${ }^{\circ} 216$ de 2004, Portaria CVS 5/ 2013, Portaria 2619/11. Pesquisa de campo e observações diretas nas Unidades de Alimentação e Nutrição. No presente estudo foram encontrados 40 \% ( $\mathrm{n}=2)$ das unidades que apresentaram layout retangular e $40 \%(n=2)$ das unidades apresentaram layout quadrado e $20 \%$ layout em formato $\mathrm{L}(\mathrm{n}=1)$ em relação à forma geométrica. Em $60 \%$ das UANs foi observada não existência de áreas distintas para despensa, preparo, refeitório, instalações sanitárias e vestiários e ausência de piso antiderrapante. Em 40\% o sistema de exaustores encontrava-se inadequado. Os resultados analisados apresentaram índices expressivos de inadequação quanto à estrutura física e aspectos de ambiência.

Palavras-chave: Estrutura dos serviços, unidade de alimentação e nutrição, fluxo de trabalho.

\begin{abstract}
Over the decades, the food and nutrition units (FNUs) have grown significantly, but often with inadequate physical structures, patterns where the big challenge is to review the concepts and their suitability. Are considered appropriate standards of physical structures to rectangular shape, layout aspects such as lighting, ventilation, floors and walls, doors and windows. This project aims to evaluate the adequacy of the physical structure of the food and nutrition units in São Paulo. Methods: this is a descriptive study, cross-sectional in nature, in a comparative perspective with the legislation in force: RDC n 275 of 2002, RDC n 216 of 2004, CVS, 52013 and Degree 2619/2011. Field research and direct observations on food and nutrition units. In this study were found $40 \%$ (n 2) presented a rectangular layout and 40 (n 2) of the square layout units and $20 \%$ L layout (n1) in relation to geometric shape. In $60 \%$ of the FNUs was observed non-existence of different areas to pantry cook, refectory, toilets and changing rooms and absence of non-slip flooring. At $40 \%$ the exautors system were inadequate. The results analyzed showed significant rates of inadequacy regarding the physical structure and aspects of ambience.
\end{abstract}

Keywords: Structure of services, food and nutrition unit, workflow. 


\section{INTRODUÇÃO}

As Unidades de Alimentação e Nutrição (UANs) são empresas que desempenham atividades relacionadas à alimentação e nutrição (TEIXEIRA et al., 2004). Observa-se aumento de atuação dessas empresas nas últimas décadas. A inserção da população feminina no mercado de trabalho, o distanciamento entre o ambiente de trabalho e domicílios e a complexidade de locomoção e transporte nos grandes centros urbanos são fatores que colaboraram para esse fato (SILVA JUNIOR, 2002; SANTOS; ALVES, 2014).

Ao longo das décadas, foi observado que muitas UANs foram planejadas em espaços adaptados de forma inadequada (ABREU et al., 2003).

A construção de UANs, com base no planejamento físico adequado é fundamental para atender às expectativas e necessidades dos clientes finais (ABREU et al., 2003).

Segundo a Portaria 2619/2011 as instalações devem ser organizadas de forma a facilitar a execução dos procedimentos operacionais, sem cruzamento de etapas e linhas do processo de produção, compreendendo desde o recebimento da matéria- prima, até a entrega do produto final para o consumo.

A forma retangular é a configuração geométrica recomendada para Unidades de Alimentação e Nutrição porque reduz caminhada desnecessária e favorece a melhora do fluxo de produção (MEZOMO et al., 2002). Além do fato de que as instalações adequadas asseguram a qualidade da produção do serviço prestado.

É recomendável que a localização do serviço de alimentação seja no andar térreo, permitindo melhor operacionalização, facilitando a iluminação e ventilação natural, contribuindo para a remoção do lixo, que pode acarretar sérios riscos de contaminação pelo odor, proliferação de microorganismos e diferentes tipos de vetores (MEZOMO et al., 2002).

De acordo com a legislação brasileira, as áreas circundantes das UANs devem ser isentas de condições para a proliferação de insetos e roedores, ser livres de objetos em desuso ou estranhos, bem como poeira, e acúmulo de lixo nas imediações (PORTARIA CVS 5, 2013).

Vários são os fatores que devem ser considerados na ambiência das UANs, alguns interferem diretamente na produção e outros proporcionam condições adequadas de trabalho (TEIXEIRA et al., 2004).

A área das UANs deverá ser planejada seguindo uma linha de produção racional. Suas unidades deverão obedecer a um fluxo contínuo, evitando cruzamento e retrocessos (TEIXEIRA et al., 2004).

Uma vez que as análises das estruturas físicas e organizacionais nessas Unidades de Alimentação e Nutrição favorecem obter visão global da estrutura produtiva disponível, salienta-se a importância de formulação de hipótese sobre possíveis falhas e a recomendação de pontos estratégicos de intervenção.

Diante da escassez de trabalhos que avaliem a adequação de estrutura física das Unidades de Alimentação e Nutrição, na cidade de São Paulo, e a relevância do tema, o presente estudo objetiva realizar essa investigação.

\section{MATERIAIS E MÉTODOS}

Trata-se de um estudo descritivo, de natureza transversal, numa perspectiva comparativa com legislação vigente. Pesquisa de campo e observação direta em Unidades de Alimentação e Nutrição.

Através de contato telefônico com os proprietários de UANs de quarenta e cinco empresas, foram questionados se gostariam de participar deste estudo. Em caso afirmativo, uma visita era programada, para apresentar os objetivos da pesquisa e coleta do consentimento do proprietário para a investigação.

Foi possível a realização da pesquisa em cinco unidades de alimentação e nutrição localizadas na cidade de São Paulo.

No dia da investigação, um termo de consentimento livre e esclarecido foi lido e assinado pelos proprietários dos estabelecimentos.

O projeto teve a aprovação pelo Comitê de Ética e Pesquisa da Universidade Paulista, sob CAAE: 17350013.4.0000.5512 e número do Parecer: 320.383.

Todas as visitas às instituições que aceitaram participar da pesquisa foram agendadas em horários e dias mais adequados aos entrevistados (administrador e/ou pessoa por ele indicada).

Considerou-se neste trabalho componentes da estrutura física, aspectos relacionados à planta física das UANs: localização, áreas e equipamentos.

As Unidades foram dimensionadas com o auxílio de uma trena de 50 metros, avaliou-se a sequência 
lógica de trabalho dos operadores por atividade, em relação ao posicionamento de cada equipamento.

Os resultados obtidos na avaliação de cada Unidade de alimentação foram comparados aos descritos pelas legislações (Resolução RDC n ${ }^{\circ} 275$ de 21 de outubro de 2002, RDC n ${ }^{\circ} 216$ de 15 de setembro de 2004, Portaria CVS 5, de 9 de abril de 2013, Portaria $2619 / 11$ ) e posteriormente os resultados foram descritos em valores percentuais.

\section{Descrição da Unidade de Alimentação e Nutrição - A}

A Unidade de Alimentação e Nutrição - A localiza-se na região central da cidade de São Paulo, o atendimento ao público ocorre das 11: $00 \mathrm{~h}$ às 23: 00 h. Essa Unidade atende demanda de 250 refeições por dia, oferece refeições na modalidade à La carte.

Possui área de estocagem de gêneros não perecíveis ampla e todas as prateleiras de aço inoxidável com distanciamento e altura adequados da parede e do piso.

Apresenta configuração geométrica retangular. Observou-se a presença de somente duas luminárias e com muitas sujidades, deixando o ambiente extremamente escuro.

A Unidade de alimentação não possui uma área especifica para o pré-preparo de alimentos e preparo; logo, os colaboradores mantêm contado com as diferentes etapas do processo.

Não apresenta um sistema de exaustores que amenize o calor do ambiente, observou-se ausência de janelas, a mesma porta de entrada dos colaboradores é utilizada para a entrada das matérias-primas e saída de lixo.

O piso é revestido de cerâmica, no entanto, não é antiderrapante e na cor cinza escuro apresenta característica impermeável e lavável. Observa-se pouco rejunte entre as peças do piso.

As paredes da área de produção de refeições eram revestidas de azulejo na cor branca, característica de material liso, sem frestas, resistente, impermeável e lavável em toda a extensão. Apresenta pequenas rachaduras.

O teto, revestido com tinta lavável branca, apresenta-se com umidade e descascamento. Iluminação com lâmpadas fluorescentes. A UAN apresenta porta com sistema vaivém e visor transparente.

\section{Descrição da Unidade de Alimentação e Nutrição - B}

A estrutura física da Unidade de Alimentação e Nutrição - B localizada na região da Zona Leste, na cidade de São Paulo, presta serviços totalizando aproximadamente 150 refeições servidas diariamente à La carte, horário de funcionamento das 7:00 h às 16:00 h. O fluxo de entrada e saída são adequados, os utensílios são recebidos, higienizados e armazenados em local específico para este fim. A área de estocagem é diretamente proporcional ao volume de refeições servidas, e as prateleiras são de alvenaria.

A área de higienização de panelas é próxima à área de cocção, e não possui separação por barreira física, favorecendo maior chance de contaminação cruzada dos alimentos. A configuração geométrica da UAN é quadrada.

O piso constituído de cerâmica, não antiderrapante, na tonalidade cinza claro, apresenta característica impermeável e lavável. As paredes da área de produção são revestidas de tinta lavável na cor branca. O teto revestido com tinta lavável branca apresenta rachaduras.

A iluminação com lâmpadas fluorescentes, sem proteção. Apresenta porta de alvenaria, com tinta óleo, não possui borracha de vedação na parte inferior.

\section{Descrição da Unidade de Alimentação e Nutrição - C}

A Unidade de Alimentação e Nutrição C está localizada na região da zona leste, na cidade de São Paulo, atende uma demanda de 100 refeições servidas ao dia na modalidade La carte, com funcionamento das 11:00 h às 16:00 horas. Apresenta configuração geométrica retangular.

A iluminação é insuficiente: possui apenas uma luminária no centro da cozinha e não possuía sistema de exaustores para amenizar o calor e retirada de fumaça; observou-se ausência de janelas.

$\mathrm{Na}$ mesma porta de entrada dos colaboradores ocorre a entrada das matérias- primas e saída de lixo. Não possui área específica para o pré-preparo de alimentos e preparos, mantendo contato com as diferentes etapas. Não segue um fluxo racional porque ocorre o cruzamento de etapas.

O piso, constituído de cerâmica antiderrapante na cor cinza escuro, apresenta característica 
impermeável e lavável, apresenta desgastes de superfície. As paredes da área de produção são revestidas de tinta lavável na cor amarelo claro. $\mathrm{O}$ teto, revestido com tinta lavável branca, possui vestígio de umidade e mofo. A iluminação com lâmpadas incandescentes está sem proteção. Apresenta porta de madeira, com tinta óleo, possui borracha de vedação na parte inferior. Prateleiras de alvenaria.

\section{Descrição da Unidade de Alimentação e Nutrição - D}

A Unidade de Alimentação e Nutrição D localiza-se na região do Centro, na cidade de São Paulo, atende 180 refeições servidas ao dia à La carte e/ou cardápio, com horário de funcionamento 9:00 h às 14:00 h. Apresenta configuração geométrica no formato L.

Foi observada iluminação artificial fora dos padrões determinados pela legislação, não possuía sistema de exaustão para amenizar o calor.

Observou-se ausência de janelas. A porta de entrada de recebimento de matéria- prima era comum à de descarte de lixo. Não possui área específica para o pré-preparo de alimentos e preparos, mantendo contado com as diferentes etapas.

As instalações sanitárias destinadas aos usuários são específicas e localizadas em local afastado da UAN.

O piso da unidade, constituído de cerâmica não antiderrapante na cor cinza escuro, apresenta característica de impermeabilidade, lavável e desgaste superficial decorrente da movimentação constante de pessoas e/ou equipamentos. As paredes da área de produção são revestidas de tintas laváveis na cor amarelo claro. O teto é revestido com tinta lavável branca.

A iluminação com lâmpadas fluorescentes, sem proteção, contribui para aumentar as chances de risco de explosões. Apresenta porta de madeira, com tinta óleo, e na parte inferior, não possuía a borracha de vedação.

\section{Descrição da Unidade de Alimentação e Nutrição - E}

A Unidade de Alimentação e Nutrição E, localizada na região da zona leste, na cidade de São Paulo, atende a demanda aproximada de 300 refeições servidas ao dia à La carte, com horário das 10:00 h às 17:00 h.
Possui pia exclusiva para a higienização das mãos. O número de colaboradores $(\mathrm{n}=8)$, permitindo um fluxo racional das etapas, devido à ausência de separação por meio físico das seguintes etapas: pré-preparo, preparo e cocção, fatores que favorecem a probabilidade de contaminação cruzada. Apresenta configuração geométrica retangular.

Possui piso constituído de cerâmica, antiderrapante, na cor branca, apresenta característica impermeável e lavável. As paredes da área de produção são revestidas de tinta lavável na cor cinza escuro. O teto é revestido com tinta lavável branca. A iluminação utiliza lâmpadas fluorescentes, sem proteção, contribuindo para risco de explosão. Apresenta porta de madeira, com tinta óleo, sem borracha de vedação na parte inferior. As prateleiras são de alvenaria.

\section{RESULTADOS E DISCUSSÃO}

Na Figura 1 é mostrado o percentual de adequação quanto à configuração geométrica das cinco Unidades de Alimentação e Nutrição na cidade de São Paulo, onde se observou que em $40 \%$ das UANs $(n=2)$ a configuração retangular foi encontrada. A configuração quadrada foi encontrada em $40 \%(n=2)$ das unidades de alimentação avaliadas, nos demais $20 \%$, observou-se a configuração em L ( $\mathrm{n}=1)$.

Figura 1 - Percentual de adequação de unidades de alimentação e nutrição na cidade de São Paulo quanto à configuração geométrica

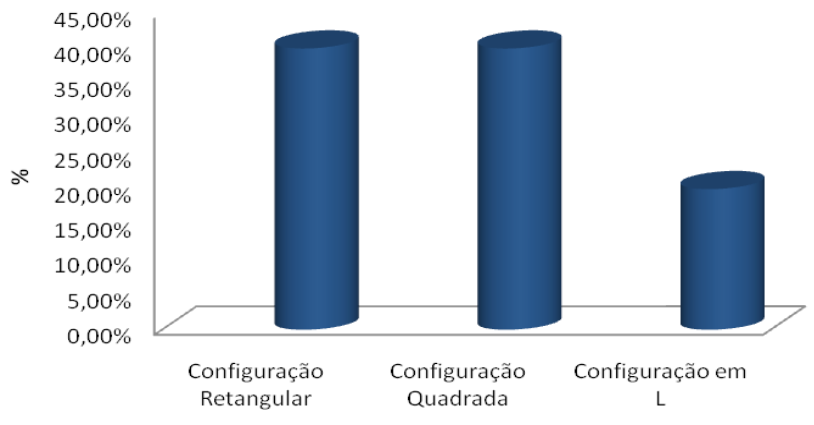

Verificou-se que $100 \%$ das UANs localizavam-se no andar térreo, fator essencial para proporcionar fácil acesso externo para o abastecimento e favorecer a iluminação natural.

Em 60\% das UANs foi observada não existência de áreas distintas para despensas, preparo, refeitório, instalações sanitárias e vestiários. 
O vestiário e sanitários em $80 \%$ das instituições não eram privativos ou separados por sexo. Esses achados são semelhantes aos encontrados por Vidal et al (2011) que avaliou as condições das instalações sanitárias e vestuários para os manipuladores de UAN de uma Organização Militar na cidade de Belém do Pará, concluíram que a quantidade de vasos sanitários, mictórios e lavatórios não encontrava-se na proporção recomendada pela legislação quanto ao número de empregados.

No presente estudo, observou-se carência de pia específica para a higienização das mãos dos manipuladores, sendo assim, a lavagem das frutas e outros alimentos era realizado na pia comum à antissepsia das mãos dos manipuladores, fato que colabora para o aumento de chance de contaminação cruzada.

De acordo com a Portaria 2619/11 a contaminação cruzada é a transferência da contaminação de uma área contaminada para a outra, por meio das mãos de manipuladores, utensílios e equipamentos.

A CVS 5 de 2013 determina que as UANs ofereçam lavatórios exclusivos para a higiene das mãos na área de manipulação, em posições estratégicas em relação ao fluxo de preparo dos alimentos e em número suficiente. Os lavatórios devem possuir sabonete líquido, neutro, inodoro e com ação antisséptica, com papel toalha descartável não reciclado ou outro procedimento não contaminante, e coletor de papel acionado sem contato manual (CVS 5, 2013).

É sabido que as cores exercem forte influência sobre as pessoas, podendo promover sensações de ânimo, excitação ou relaxamento (PINHEIRO, 2011). O creme, amarelo palha, amarelo e rosa claro são cores adequadas para o revestimento das paredes. Em cozinhas industriais este fato nem sempre é comprovado, devido à larga utilização de materiais e equipamentos comumente confeccionados em aço inoxidável, que interferem no índice de reflexão, favorece a ocorrência de ambientes escuros, quando não se utiliza o branco (TEIXEIRA et al. ,2004). No presente estudo em $20 \%$ das UANs avaliadas as cores das paredes encontravam-se inadequadas com o preconizado por lei.

Outro ponto a ser considerado é quanto ao tipo de piso a ser utilizado na UAN, sendo o antiderrapante o mais indicado, uma vez que favorece ambiente de maior proteção contra acidentes para os manipuladores. No presente estudo, o piso não era antiderrapante em $60 \%$ das unidades de alimentação e nutrição.
Observou-se existência de azulejos, pisos quebrados, mofo ou sinais de goteiras em $60 \%$ das instituições avaliadas.

Em $20 \%$ das UANs analisadas não foram observados telas de proteção nas janelas, contra insetos, roedores e controle de vetores.

A luz era fluorescente em $60 \%$ das instituições, mas a disposição das luminárias, o distanciamento entre uma a outra foi observado como adequado em somente $20 \%$ das empresas. Constata-se uma acentuada tendência para o uso de lâmpada fluorescentes nas UAN, por ser a iluminação branca o tipo mais adequado, por manter a cor natural dos alimentos, e não contribuir para a elevação da temperatura no local.

A abertura de janelas no posicionamento e distanciamento entre uma e outra visa assegurar a iluminação natural e melhoria do conforto térmico dos manipuladores (FARIA, 1983). No entanto, em todas as UANs avaliadas a quantidade e posição das janelas encontravam-se inadequadas, usando-se como critério as orientações da legislação.

As portas de comunicação entre algumas áreas devem possuir um visor, para evitar choque entre os colaboradores que circulam e devem ser dotadas de sistema vaivém. Observou-se inadequação em $80 \%$ das unidades avaliadas. A borracha de vedação na extremidade inferior das portas encontrava-se com desgaste em $80 \%$ das unidades, inclusive nas de acesso ao estoque de gêneros não perecíveis (TEIXEIRA, 2004).

No tocante à importância de sistema de exaustão, esse auxilia na extração de gordura, vapor, gases, fumaça, calor e odores. No entanto em $40 \%$ das UANs, o sistema de exaustão encontrava-se inadequado (TEIXEIRA, 2004).

A estrutura física de uma unidade de alimentação, bem como o trabalho do manipulador de alimentos, é fundamental para garantir alimentos mais seguros e proteger a saúde dos consumidores (PROENÇA, 2005).

Os equipamentos e as mãos de manipuladores são potenciais causadores de contaminação de alimentos. Todavia, fatores como a qualidade da matéria-prima, condições ambientais, características dos equipamentos usados na preparação e as condições técnicas de higienização são pontos importantes na epidemiologia das doenças transmissíveis por alimentos. Nenhum destes aspectos supera a importância das técnicas de 
manipulação e a própria saúde do manipulador nesta particularidade.

As práticas inadequadas de higiene e processamento de alimentos por pessoas inabilitadas podem provocar a contaminação cruzada de alimentos, o que constitui um potencial problema de saúde pública (SOUZA, 2004; SANTOS, 2015).

De acordo com a legislação é proibida a existência de objetos em desuso ao redor da área da UANs. Todavia, nesse aspecto, em 100\% das unidades de alimentação foram encontrados equipamentos e/ou móveis em desuso ao redor das UANs avaliadas.

Trabalhos desenvolvidos por VIDAL et al., (2011) e AKUTSU et al., (2005) encontraram resultados semelhantes nas UANs avaliadas quanto à presença de objetos em desuso ao redor das UANs avaliadas.

Consideram-se como visitantes todas as pessoas que não fazem parte da equipe de funcionários da área de manipulação de alimentos, podendo constituir focos de contaminação. Todos os visitantes (supervisores, consultores, fiscais, auditores, e todos aqueles que necessitem entrar nas dependências das UANs) devem estar devidamente paramentados com uniforme fornecido pela empresa, como avental, rede ou gorro para proteção dos cabelos e, se necessário, botas protetoras para os pés (CVS 5, 2013). Sendo assim, foi verificado que em $80 \%(n=4)$ das unidades avaliadas não havia a paramentação para os visitantes, como rede ou touca descartáveis para utilização dos visitantes.

Os resultados encontrados no presente estudo confirmam os resultados encontrados por AKUTSU et al (2005) na região de Brasília em 50 estabelecimentos produtores de alimentos cuja conclusão foi que os restaurantes comerciais apresentam-se com maiores índices de inadequação quanto aos itens edificação, manipulação e fluxo de produção quando comparados às UANS da linha hoteleira.

\section{CONCLUSÃO}

A recusa de quarenta unidades de alimentação e nutrição para a participação nessa pesquisa denota a evidência de possíveis falhas na adequação das estruturas físicas dessas UANs. A recusa de muitas empresas e o livre arbítrio para contribuir em pesquisas ainda é um grande desafio para esse tipo de investigação.

No entanto, os resultados analisados das cinco empresas avaliadas apresentaram índices expressivos de inadequação quanto à estrutura física e aspectos de ambiência e a existência de lacunas sob a ótica da produção de alimentos seguros.

O presente estudo revela déficit de conhecimento dos manipuladores de alimentos e proprietários em relação às Boas Práticas de Fabricação, apontando a necessidade de adequação das estruturas físicas, para que estes estejam aptos a produzir alimentos que não coloquem em risco a saúde dos clientes.

Falhas na estrutura física podem favorecer o risco de contaminação cruzada nos alimentos, bem como prejuízos na otimização do trabalho dos colaboradores e aumento de chance de acidente no trabalho. Nesse aspecto, apesar das limitações apresentadas no presente estudo, foi possível atingir os objetivos propostos; no entanto, os autores sugerem a realização de novos estudos, com maior número de empresas investigadas.

\section{REFERENCIAS}

ABREU, E.S; SPNINELLI, M.G.N; ZANARDI, A.M.P. Gestão de Unidades de Alimentação e Nutrição: um modo de fazer. São Paulo: Metha Ltda, 2003.

AKUTSU,R.C. et al.Adequação das boas práticas de fabricação em serviços de alimentação. Revista de Nutrição, Campinas, v.18, n.3, p.419-427, 2005.

BRASIL. Portaria ${ }^{\circ}$ 2619/11. Estabelece Novas Regras para Profissionais que Atuam com a Manipulação de Alimentos, considerando as Disposições Contidas nos Artigos n ${ }^{\circ} 10,45$ e 46 da Lei Municipal no 13.725, de 09 de janeiro de 2004. D.O.U.06/12/2011.

BRASIL. Portaria CVS 5 de 09 de abril de 2013. Aprova o Regulamento Técnico Sobre Boas Práticas para Estabelecimentos Comerciais de Alimentos e para Serviços de Alimentação, e o Roteiro de Inspeção. D.O.U. de 05/04/2013.

BRASIL. Resolução RDC $\mathrm{n}^{\circ} 275$ de 21 de outubro de 2002. Dispõe sobre o Regulamento Técnico de Procedimentos Operacionais Padronizados aplicados aos Estabelecimentos Produtores/Industrializadores de Alimentos e a Lista de Verificação das Boas Práticas de Fabricação em Estabelecimentos Produtores/Industrializadores de Alimentos.D.O.U. de 06/11/2002.

BRASIL. Resolução RDC n50, de 21 de fevereiro de 2002. Dispõe sobre o Regulamento Técnico para Planejamento, Programação, Elaboração e Avaliação de Projetos Físicos de Estabelecimentos Assistenciais de Saúde. D.O.U. de 20/3/2002. 
BRASIL. Resolução RDC n²16 de 15 de setembro de 2004. Dispõe sobre o Regulamento Técnico de Boas Práticas para Serviços de Alimentação. D.O.U. de 16/09/2004.

FARIA, N.A. Organização e métodos. Rio de Janeiro: Pirâmide, 1983.p.38.

MEZOMO, I.F.B. Os serviços de alimentação: planejamento e administração. 5. ed. São Paulo: Manole, 2002.p.122-163.

SANT'ANA, H.M.P. Planejamento físico-funcional de Unidades de Alimentação e Nutrição. Rio de Janeiro: Rubio, 2012.

PROENÇA, R.P.C. Qualidade nutricional e sensorial na produção de refeições. Florianópolis: UFSC, 2005.p.221.

SANTOS, V.F.N.; ALVES, M.A.A. Unidades de alimentação e nutrição no Brasil:Conhecendo o perfil de seus pesquisadores.Revista Científica Linkania Master. v.1,n. 9, p.86, 2014.

SANTOS, V.F.N.; BASSI, S.M. Avaliação da temperatura dos equipamentos e alimentos servidos em unidades de alimentação e nutrição na cidade de São Paulo. Revista Científica Linkania Master, v.5, n.1, p.113, 2015.

SILVA JR., E. A. Manual de Controle HigiênicoSanitário em Alimentos. 5 ed. São Paulo: Varela,2002.p.259-260.

SOUZA, E.L.; SILVA, C.A.; SOUSA, C.P. Qualidade sanitária de equipamentos, superfícies, água e mãos de manipuladores de alguns estabelecimentos que comercializam alimentos na cidade de João Pessoa, PB. Revista Higiene Alimentar, v.18, $\mathrm{n}^{\circ} 116 / 117$, p 98-103, 2004.

TEIXEIRA, S.M.F.G. et al. Administração Aplicada às Unidades de Alimentação e Nutrição. Editora Atheneu, São Paulo, Rio de Janeiro, Ribeirão Preto, Belo Horizonte, 2004.p. 15; 82 .

VIDAL,G.M. et al. Avaliação das Boas Práticas em Segurança Alimentar de uma Unidade de Alimentação e Nutrição de uma Organização Militar da Cidade de Belém,Pará. Alimentos e Nutrição, Araraquara, v.22, n.2, p.283-290, 2011. 